\title{
Short- and long-term outcomes of aortic root repair and replacement in patients undergoing acute type $A$ aortic dissection repair: Twenty-year experience
}

Bo Yang, MD, PhD, ${ }^{\text {a }}$ Elizabeth L. Norton, MS, ${ }^{\text {a }}$ Reilly Hobbs, MD, MBS, ${ }^{a}$ Linda Farhat, MS, ${ }^{a}$ Xiaoting Wu, PhD, ${ }^{a}$ Whitney E. Hornsby, PhD, ${ }^{\mathrm{b}}$ Karen M. Kim, MD, ${ }^{\mathrm{a}}$ Himanshu J. Patel, MD, ${ }^{\mathrm{a}}$ and G. Michael Deeb, MD

\section{ABSTRACT}

Objective: The study objective was to evaluate the perioperative and long-term outcomes of aortic root repair and aortic root replacement and provide evidence for root management in acute type A aortic dissection.

Methods: From 1996 to 2017, 491 patients underwent aortic root repair ( $\mathrm{n}=307$ ) or aortic root replacement $(n=184)(62 \%$ bioprosthesis $)$ for acute type A aortic dissection. Indications for aortic root replacement were intimal tear at the aortic root, root measuring $4.5 \mathrm{~cm}$ or more, connective tissue disease, or unrepairable aortic valvulopathy. Primary outcomes were in-hospital mortality, long-term survival, and reoperation rate for root pathology.

Results: Patients' median age was 61 years and 56 years in the aortic root repair group and aortic root replacement group, respectively. The aortic root replacement group had more renal failure requiring dialysis, previous cardiac intervention or surgery, heart failure, coronary malperfusion syndrome, acute myocardial infarction, and severe aortic insufficiency, as well as concomitant coronary artery bypass grafting, tricuspid valve repair, and longer cardiopulmonary bypass and aortic crossclamp times but similar arch procedures. Perioperative outcomes were similar in the aortic root repair and aortic root replacement groups, including in-hospital mortality $(8.5 \%$ and $8.2 \%)$, new-onset renal failure requiring permanent dialysis, stroke, myocardial infarction, and sepsis. KaplanMeier 10-year survival was $62 \%$ and $65 \%$, and the 15 -year cumulative incidence of reoperation was $11 \%$ and $7 \%$ in the aortic root repair and aortic root replacement groups, respectively. The primary indication for root reoperation was aortic root aneurysm in the aortic root repair group and bioprosthetic valve deterioration in the aortic root replacement group.

Conclusions: Aortic root repair and aortic root replacement are appropriate surgical options for acute type A aortic dissection repair with favorable short- and long-term outcomes. Aortic root replacement should be performed for patients with acute type A aortic dissection presenting with an intimal tear at the aortic root, root aneurysm $4.5 \mathrm{~cm}$ or greater, connective tissue disease, or unrepairable aortic valvulopathy. (J Thorac Cardiovasc Surg 2019;157:2125-36)

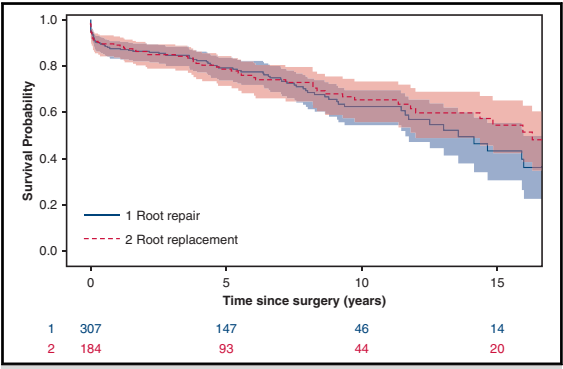

Kaplan-Meier survival of patients undergoing ARr and ARR.

\section{Central Message}

Properly selected patients with ATAAD can undergo ARr or ARR with favorable short- and long-term survival based on the predefined criteria of ARR.

\section{Perspective}

Patients with ATAAD with intimal tear at the aortic root, root aneurysm $4.5 \mathrm{~cm}$ or greater, connective tissue disease, or unrepairable aortic valvulopathy should undergo ARR. In the absence of those criteria, ARr with preservation of the aortic root is an appropriate option, but with a potential risk of reoperation for an aortic root aneurysm, especially in young male patients.

See Commentary on page 2137.

\footnotetext{
From the Departments of ${ }^{\mathrm{a} C a r d i a c}$ Surgery and ${ }^{\mathrm{b}}$ Internal Medicine, Michigan Medicine, Ann Arbor, Mich.

Funding: B.Y. is supported by the National Heart, Lung, and Blood Institute of National Institutes of Health K08HL130614, R01HL141891, the Phil Jenkins Breakthrough Fund, and Darlene \& Stephen J. Szatmari Funds. H.J.P. is supported by the Joe D. Morris Collegiate Professorship, the David Hamilton Fund, and the Phil Jenkins Breakthrough Fund in Cardiac Surgery.

Date and number of Institutional Review Board approval: HUM00118824, approved October 7, 2016.

B.Y. and E.L.N. contributed equally as co-first authors.
}

Read at the 98th Annual Meeting of The American Association for Thoracic Surgery, San Diego, California, April 28-May 1, 2018.

Received for publication April 11, 2018; revisions received Aug 15, 2018; accepted for publication Sept 12, 2018; available ahead of print Feb 6, 2019.

Address for reprints: Bo Yang, MD, PhD, 1500 East Medical Center Drive, 5155 Frankel Cardiovascular Center, Ann Arbor, MI 48109 (E-mail: boya@med umich.edu). $0022-5223 / \$ 36.00$

Copyright $(2018$ by The American Association for Thoracic Surgery https://doi.org/10.1016/j.jtcvs.2018.09.129 


\section{Abbreviations and Acronyms \\ $\mathrm{ARr}=$ aortic root repair \\ ARR = aortic root replacement \\ ATAAD $=$ acute type A aortic dissection \\ CI = confidence interval \\ $\mathrm{HR}=$ hazard ratio \\ NYHA $=$ New York Heart Association \\ STJ = sinotubular junction \\ VSARR $=$ valve-sparing aortic root replacement}

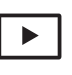

Scanning this QR code will take you to the article title page to access supplementary information. To view the AATS Annual Meeting Webcast, see the URL next to the webcast thumbnail.

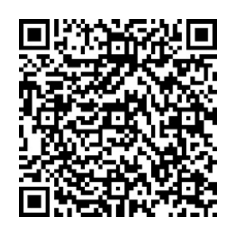

Acute type A aortic dissection (ATAAD) is a catastrophic event associated with a high risk of operative morbidity and mortality. At present, 30-day mortality remains between $20 \%$ and $25 \% .^{1-3}$ ATAAD frequently involves dissection of the aortic root, sometimes with a primary tear involving the intima of the aortic root. It is also common to see patients with ATAAD with root pathology in addition to aortic dissection, such as root aneurysm or aortic valve pathology. The operative goal for ATAAD is to prevent aortic rupture with subsequent tamponade by replacing the proximal aorta; however, the appropriateness of concurrently treating any associated aortic root pathology to decrease the risk of a later reoperation remains debatable. It is a fine line between the extent of the operative procedure to salvage the patient from a catastrophic event and aggressively treating the aortic root pathology to prevent later aortic root events, including aortic insufficiency, root aneurysm, and reoperation.

Criteria have yet to be established to guide surgeons on whether to perform aortic root replacement (ARR) or aortic root repair (ARr) in ATAAD. ${ }^{2-8}$ The published outcomes are inconsistent because some studies show no difference in operative mortality between ARR and aortic root repair (ARr), ${ }^{6-9}$ whereas another study indicates lower operative mortality in the ARr group. ${ }^{10}$ Furthermore, there is inconsistency as to whether the preserved aortic root in patients with ATAAD is $\operatorname{stable}^{3,11,12}$ or a risk factor for later reoperation. $2,5,13,14$

In this study, we analyzed the short- and long-term outcomes of patients with ATAAD who underwent ARr with preservation of the whole aortic root (including the aortic valve and all sinuses of Valsalva) or ARR with a whole root prosthesis or valve-sparing aortic root replacement (VSARR). We hypothesized that with predefined criteria for ARR or ARr, ARR would not increase perioperative mortality, and ARr would not increase the risk of late reoperation for aortic root events.

\section{MATERIALS AND METHODS}

This study was approved by the University of Michigan Institutional Review Board (Michigan Medicine, Ann Arbor, Mich), and a waiver of consent was obtained.

\section{Study Population}

Between July 1996 and January 2017, 491 patients underwent ARr $(\mathrm{n}=307)$ or ARR $(\mathrm{n}=184)$ with inclusion/modified inclusion $(\mathrm{n}=70$, $38 \%)$, Bentall procedure $(n=69,38 \%)$, and VSARR $(n=45,24 \%)$ for ATAAD. The ARr group included aortic root reconstruction with preservation of the aortic valve with all native aortic root tissue $(n=307)$. The ARR group had a mechanical composite valve graft $(n=26,14 \%)$, Freestyle porcine aortic root (Medtronic Inc, Minneapolis, Minn) $(\mathrm{n}=113$, $62 \%)$, or valve-sparing root $(n=45,24 \%)$.

\section{Data-Collection Techniques}

Investigators obtained Society of Thoracic Surgery data elements from the University of Michigan Department of Cardiac Surgery Data Warehouse to determine preoperative, intraoperative, and postoperative characteristics as previously reported. ${ }^{15}$ Medical records, including operative reports, were reviewed to supplement data collection. Events of reoperation included open repair (sternotomy) or transcatheter aortic valve replacement for aortic root pathology only. Reoperation primarily for arch, descending thoracic, or thoracoabdominal aortic aneurysm was not included as an event of reoperation. Survival data were collected through the National Death Index database through December 31, 2015. ${ }^{16}$ Further survival data and reoperation data were collected from a thorough medical record review of patients' return visits and surveys (including letters and phone calls) through January 2018. Loss of follow-up or end of the study period was treated as a censor during the time to events analyses. Of 491 patients, we had follow-up regarding reoperation and long-term events for 385 (78.4\%); 106 patients $(11.6 \%)$ did not respond to the survey, including 33 patients who were dead and 73 patients who were still alive. The median follow-up time was 4.7 (25th and 75 th percentiles: $[1.8,7.8]$ ) years, and the mean follow-up time was 5.8 years, because $62 \%$ (303/491) of all cases were performed in the second decade (2008-2017).

\section{Operative Techniques}

The indication for ARR in patients with ATAAD included (1) intimal tear at the aortic root, (2) root diameter $4.5 \mathrm{~cm}$ or greater, (3) connective tissue disease, and (4) unrepairable aortic valve pathology. The ARR was performed as a Bentall procedure by resecting all the aortic root tissue, replacing the aortic root with a mechanical composite valve graft (St Jude Medical, St Paul, Minn; Medtronic Hall, Medtronic Inc) or Freestyle stentless porcine aortic root (Medtronic Inc), and reimplanting 2 separate coronary buttons with full-thickness bites through the coronary buttons circumferentially. The inclusion/modified inclusion ARR was performed by including the prosthetic aortic root in the native aortic root, and 2 coronary ostia were reimplanted as a side-to-side fashion but with fullthickness bites. VSARR was performed using the Yacoub remodeling technique $(\mathrm{n}=5)$ and David reimplantation technique $(\mathrm{n}=40)$. Valsalva graft or straight tubular grafts (2-graft technique) were used in the David procedure based on the surgeon's preference as described in our previous 
publication. ${ }^{17}$ All 3 techniques of ARR, including inclusion technique, Bentall procedure, and David procedure, are current practice in our group.

If patients did not meet the criteria for ARR, the aortic root was repaired by preserving the aortic valve and all sinus of Valsalva tissue to maintain the normal geometry of the aortic root, even if the aortic dissection involved all sinuses of Valsalva and extended down to the aortic annulus. Direct repair of the aortic root consisted of trimming the aortic root 3 to $5 \mathrm{~mm}$ above the sinotubular junction (STJ) or coronary ostia, whichever was more distal. All thrombus in the false lumen was removed from each sinus of Valsalva. Reconstruction of the aortic root was performed per surgeon preference and included reapproximation of the aortic wall at the STJ with running circumferential 5-0 Prolene with no use of any surgical technical adjuncts, ${ }^{18}$ inverting adventitia as a buttress for the proximal anastomosis ${ }^{19}$ or placing felt in the false lumen to create "neo-media" and using felt as a buttress for proximal anastomosis. ${ }^{20}$ The direct repair of the aortic root without surgical technical adjuncts was performed by reapproximating the 2 layers of dissected aortic wall of the root at the STJ with 5-0 Prolene in running suture fashion circumferentially. If the dissection went down around the coronary ostia, then the aortic sinus wall was reinforced with 5-0 Prolene in running suture fashion around the coronary ostia circumferentially as an in situ coronary button reimplantation with fullthickness bites of both layers of dissected aortic sinus wall. ${ }^{18}$ Biological glue was used for the aortic root reconstruction only from 1999 to 2004. We abandoned biological glue because of its toxicity and associated formation of anastomotic pseudoaneurysms. The aortic valve was resuspended at the 3 commissural posts with pledgeted 4-0 Prolene sutures. The repaired aortic root was then anastomosed to the Dacron graft.

\section{Statistical Analysis}

Because the ARr and ARR groups are 2 significantly different groups at baseline, we conducted this study as a descriptive study instead of comparing the outcomes between the 2 groups. Data are presented as median (interquartile range, 25 th and 75 th percentile) for continuous data and $\mathrm{n}(\%)$ for categoric data. Crude survival curves for time to death since operation were estimated using the nonparametric Kaplan-Meier method. Cox proportional hazards regression was used to calculate the adjusted hazard ratios (HRs) with $95 \%$ confidence interval (CI) for survival by adjusting age, gender, hypertension, New York Heart Association (NYHA) class, coronary artery disease, acute myocardial infarction, preoperative severe aortic insufficiency, renal failure, previous cardiac intervention and surgery, and operative technique (root repair or root replacement) in the whole cohort. Because patients may die before reoperation, cumulative incidence curves were generated to assess the reoperation rates for primarily aortic root pathology over time adjusting for death as the competing risk. Incidence rates were calculated for long-term events (eg, stroke, transient ischemic attack, endocarditis, reoperation for aortic root aneurysm), in which the numbers of events were divided by total patient-years of follow-up.

\section{RESULTS}

\section{Demographics and Preoperative Data}

This is a typical cohort of patients with ATAAD. The ARR group was predominately male and younger, and had more renal failure requiring hemodialysis, previous cardiac intervention (eg, percutaneous coronary intervention), previous cardiac surgery, heart failure (NYHA III-IV), acute myocardial infarction and coronary malperfusion syndrome, severe aortic insufficiency, and Marfan syndrome. Both groups had similar malperfusion syndromes in other organs, including cerebral, spinal cord, celiac/hepatic, mesenteric, renal, and extremities (Table 1).

\section{Intraoperative Data}

The ARr group had more arch replacement, but the use of ACP or RCP was similar in both groups. The ARR group had more concomitant coronary artery bypass grafting and tricuspid valve repairs, as well as longer cardiopulmonary bypass and aortic crossclamp times (Table 2).

\section{Perioperative Outcomes}

In both the ARr and ARR groups, 30-day mortality, inhospital mortality, and operative mortality (including mortality within 30 days after surgery or mortality in hospital) were $8 \%$ to $9 \%$. The rate of new-onset stroke, paraplegia, myocardial infarction, renal failure requiring permanent dialysis, reoperation for bleeding, sepsis, intubation time, and length of intensive care unit or hospital stay were similar between the 2 groups (Table 3). By 90 days, the ARr group had 30 deaths, and Kaplan-Meier survival was 90\% (95\% CI, 86-93); the ARR group had 17 deaths, and Kaplan-Meier survival was $91 \%$ (95\% CI, 86-94).

\section{Long-Term Outcomes}

There were 98 late deaths observed within the entire cohort (ARr group, $\mathrm{n}=59$ and ARR group, $\mathrm{n}=39$ ). The KaplanMeier 10-year and 15-year survivals were 64\% (95\% CI, 5869) and $49 \%(95 \%$ CI, 40-57) for the entire cohort (Figure 1, A) ; $62 \%$ (95\% CI, 54-70) and $43 \%$ (95\% CI, 30-55) for the $\mathrm{ARr}$ group; and $65 \%(95 \% \mathrm{CI}, 56-73)$ and $54 \%(95 \% \mathrm{CI}$, 42-65) for the ARR group, respectively (Figure 1, B). Age, coronary artery disease, and NYHA class 3 and 4 were significant risk factors for all-time mortality after surgery $\left(\mathrm{HR}_{\mathrm{age}}=1.04, P<.0001, \mathrm{HR}_{\mathrm{CAD}}=1.73, P=.007\right.$, and $\left.\mathrm{HR}_{\mathrm{NYHA}}=1.50, P=.035\right)$. Operative technique (ARr or ARR) was not a significant risk factor.

The cumulative incidence of reoperations primarily for aortic root pathology only after the initial ATAAD procedure at 10 years and 15 years was $6.5 \%$ and $11 \%$, respectively, in the ARr group and $4.7 \%$ and $7 \%$, respectively, in the ARR group (Figure 2). The primary indication of reoperation in the $\operatorname{ARr}$ group $(n=9)$ was aortic root aneurysm $(0.5 \%$ / year) (Table 4), the median interval time between ATAAD repair and reoperation was 6 years with 8 of 9 patients being male (Table 5), and the reoperations were all aortic root replacements (2 VSARRs, 9 bioprosthetic Bentall, and 2 mechanical Bentall). The primary indication in the ARR group $(\mathrm{n}=6)$ was all structural valve deterioration $(0.5 \% /$ year) (Table 4$)$, the median interval time was 8.5 years, and the reoperations included 4 redo-root replacements (3 bioprosthetic and 1 mechanical Bentalls) and 2 transcatheter aortic valve replacements (CoreValve, Medtronic).

\section{DISCUSSION}

In this study, we reported our 20-year experience of treating 491 patients with ARr or ARR (62\% with bioprosthesis) 
TABLE 1. Demographics and preoperative outcomes

\begin{tabular}{|c|c|c|c|}
\hline Variables & Total $(n=491)$ & Root repair $(n=307)$ & Root replacement $(n=184)$ \\
\hline Patient age (y) & $59(49,68)$ & $61(52,69)$ & $56(44,67)$ \\
\hline$\leq 60 \mathrm{y}$ & $269(55)$ & $153(50)$ & $116(63)$ \\
\hline Gender, female & $147(30)$ & $109(36)$ & $38(21)$ \\
\hline BSA & $2.1(1.9,2.2)$ & $2.0(1.9,2.2)$ & $2.1(1.9,2.2)$ \\
\hline \multicolumn{4}{|l|}{ Preexisting comorbidities } \\
\hline Hypertension & $343(70)$ & 234 (76) & 109 (59) \\
\hline Diabetes mellitus & $33(6.7)$ & $23(7.5)$ & $10(5.4)$ \\
\hline History of smoking & $269(55)$ & $176(57)$ & $93(51)$ \\
\hline CAD & $87(19)$ & $50(17)$ & $37(21)$ \\
\hline COPD & $47(9.6)$ & $26(8.5)$ & $21(11)$ \\
\hline History of stroke & $13(2.6)$ & $7(2.3)$ & $6(3.3)$ \\
\hline History of renal failure & $23(4.7)$ & $11(3.6)$ & $12(6.5)$ \\
\hline On dialysis & $12(2.4)$ & $6(2.0)$ & $6(3.3)$ \\
\hline MFS & $13(2.6)$ & $0(0)$ & $13(7.1)$ \\
\hline LDS & $1(0.2)$ & $0(0)$ & $1(0.5)$ \\
\hline PVOD & $61(12)$ & $38(12)$ & $23(13)$ \\
\hline Previous cardiac intervention & $68(14)$ & $36(12)$ & $32(17)$ \\
\hline Previous cardiac surgery & $41(8.4)$ & $20(6.5)$ & $21(11)$ \\
\hline \multicolumn{4}{|l|}{ Aortic valve morphology } \\
\hline Unicuspid/bicuspid & $44(9.0)$ & $9(2.9)$ & $35(19)$ \\
\hline Tricuspid & $380(77)$ & $264(86)$ & $116(63)$ \\
\hline Quadricuspid & $1(0.2)$ & $1(0.3)$ & $0(0)$ \\
\hline Unknown & $66(13)$ & $33(11)$ & $33(18)$ \\
\hline \multicolumn{4}{|l|}{ Preoperative AI } \\
\hline None & $121(26)$ & $97(32)$ & $24(13)$ \\
\hline Trace & $50(11)$ & $44(14)$ & $6(3.3)$ \\
\hline Mild & $90(19)$ & $68(22)$ & $22(12)$ \\
\hline Moderate & $81(17)$ & $50(16)$ & $31(17)$ \\
\hline Severe & $122(26)$ & $33(11)$ & $89(48)$ \\
\hline Ejection fraction & $55(50,60)$ & $55(50,60)$ & $55(50,60)$ \\
\hline \multicolumn{4}{|l|}{ NYHA function class } \\
\hline III/IV & $107(23)$ & $57(19)$ & $50(27)$ \\
\hline Acute myocardial infarction & $17(3.5)$ & $6(2.0)$ & $11(6.0)$ \\
\hline Acute stroke & $22(4.5)$ & $13(4.2)$ & $9(4.9)$ \\
\hline Acute renal failure & $67(14)$ & $44(14)$ & $23(12.5)$ \\
\hline Acute paralysis & $8(1.6)$ & $7(2.3)$ & $1(0.5)$ \\
\hline Cardiogenic shock & $48(9.8)$ & $26(8.5)$ & $22(12)$ \\
\hline Tamponade & $47(9.6)$ & $31(10)$ & $16(8.7)$ \\
\hline Preoperative creatinine & $1.0(0.8,1.3)$ & $1.0(0.8,1.3)$ & $1.0(0.8,1.4)$ \\
\hline \multicolumn{4}{|l|}{ Malperfusion } \\
\hline Coronary & $17(3.5)$ & $7(2.3)$ & $10(5.4)$ \\
\hline Cerebral & $21(4.1)$ & $12(3.9)$ & $9(4.9)$ \\
\hline Spinal cord & $8(1.6)$ & $7(2.3)$ & $1(0.5)$ \\
\hline Celiac/hepatic & $8(1.6)$ & $4(1.3)$ & $4(2.2)$ \\
\hline Mesenteric & $42(8.6)$ & $28(9.1)$ & $14(7.6)$ \\
\hline Renal & $36(7.3)$ & $22(7.2)$ & $14(7.6)$ \\
\hline Extremity & $42(8.6)$ & $30(10)$ & $12(6.5)$ \\
\hline Delayed operation & $72(15)$ & $47(15)$ & $25(14)$ \\
\hline
\end{tabular}

Data presented as median $(25 \%, 75 \%)$ for continuous data and $\mathrm{n}(\%)$ for categoric data. $B S A$, Body surface area; $C A D$, coronary artery disease; $C O P D$, chronic obstructive pulmonary disease; MFS, Marfan syndrome; LDS, Loeys-Dietz syndrome; PVOD, peripheral vascular occlusive disease; AI, aortic insufficiency; NYHA, New York heart Association. 
TABLE 2. Intraoperative outcomes

\begin{tabular}{|c|c|c|c|}
\hline Variables & Total $(n=491)$ & Root repair $(n=307)$ & Root replacement $(n=184)$ \\
\hline No arch replacement & $30(6.1)$ & $7(2.3)$ & $23(12.5)$ \\
\hline Arch replacement & $461(94)$ & $300(98)$ & $161(87.5)$ \\
\hline Hemi-arch & $295(60)$ & $178(58)$ & $117(64)$ \\
\hline Zone 1 arch & $40(7.9)$ & $24(7.8)$ & $16(8.7)$ \\
\hline Zone 2 arch & $95(20)$ & $75(24)$ & $20(11)$ \\
\hline Total arch (zone 3$)$ & $31(6.3)$ & $23(7.8)$ & $8(4.3)$ \\
\hline Elephant trunk & $24(4.9)$ & $17(5.5)$ & $7(3.8)$ \\
\hline CPB time (min) & $223(182,274)$ & $203(169,241)$ & $265(224,300)$ \\
\hline Crossclamp time (min) & $159(117,204)$ & $129(106,159)$ & $214(181,248)$ \\
\hline $\mathrm{HCA}$ & $463(94)$ & $300(98)$ & $163(89)$ \\
\hline HCA time (min) & $34.5(27,45)$ & $36(28,45)$ & $32(24,42)$ \\
\hline \multicolumn{4}{|l|}{$\mathrm{ACP}$ or $\mathrm{RCP}$} \\
\hline $\mathrm{ACP}$ & $149(30)$ & $99(32)$ & $50(27)$ \\
\hline $\mathrm{RCP}$ & $187(38)$ & $111(36)$ & $76(41)$ \\
\hline Both ACP and RCP & $124(25)$ & $87(28)$ & $37(20)$ \\
\hline \multicolumn{4}{|l|}{ Concomitant operations } \\
\hline CABG & $29(5.9)$ & $13(4.2)$ & $16(8.7)$ \\
\hline MV & $2(0.4)$ & $0(0)$ & $2(1.1)$ \\
\hline TV & $7(1.4)$ & $2(0.7)$ & $5(2.7)$ \\
\hline \multicolumn{4}{|c|}{ Blood transfusions (PRBCs) } \\
\hline 0 units & $95(20)$ & $64(22)$ & $31(18)$ \\
\hline 1 unit & $35(7.5)$ & $21(7.2)$ & $14(8.0)$ \\
\hline 2 units & $41(8.8)$ & $24(8.2)$ & $17(10)$ \\
\hline$\geq 3$ units & $297(63)$ & $183(63)$ & $114(65)$ \\
\hline
\end{tabular}

Data presented as median $(25 \%, 75 \%)$ for continuous data and $\mathrm{n}(\%)$ for categoric data. Hemiarch: Aortic arch was resected from the base of innominate artery to the base of left subclavian artery, then lesser curvature; no reimplantation of arch branches. Zone $1 \mathrm{arch}$ : Aortic arch was divided between innominate artery and left common carotid artery with reimplantation of innominate artery or right common carotid artery and right subclavian artery separately. Zone 2 arch: Aortic arch was divided between left common carotid artery and left subclavian artery with reimplantation of innominate artery and left common carotid artery; or right subclavian artery, right common carotid artery, and left common carotid artery separately Zone 3 arch: Aortic arch was divided distal to the left subclavian artery with reimplantation of all arch branches. $C P B$, Cardiopulmonary bypass; $H C A$, hypothermic circulatory arrest; $A C P$, antegrade cerebral perfusion; $R C P$, retrograde cerebral perfusion; $C A B G$, coronary artery bypass grafting; $M V$, mitral valve; $T V$, tricuspid valve; $P R B C$, packed red blood cells.

based on predefined criteria to guide the operative approach. We report that in-hospital mortality was between $8 \%$ and $9 \%$ for both groups with similar long-term survival. The primary reason for reoperation was aortic root aneurysm in the ARr group and structural valve deterioration in the ARR group (Video 1).

Management of the aortic root in ATAAD is controversial. With our main priority being to maximize perioperative survival, we used 4 criteria to determine whether to perform an ARR as follows:

1. Intimal tear in the aortic root: When the intimal flap has a tear in the sinus of Valsalva, it is hard to repair and the repair is not sustained. Because of the tear, without ARR there is a persistent risk for rupture, aortic valvulopathy/insufficiency, or coronary artery dissection and malperfusion, as well as rapid aneurysmal degeneration necessitating reoperation. The tear needs to be resected, and the root needs to be replaced.
2. Connective tissue disease: Patients with connective tissue disease have a higher risk of developing an aortic root aneurysm after aortic dissection even if they do not have a root aneurysm at the time of dissection; consequently, there is a higher risk of reoperation for an aortic root aneurysm or aortic insufficiency. ${ }^{5,13,21}$ In our ARr group, 9 patients underwent reoperation for aortic root aneurysm. Two of 9 patients had a new diagnosis of Marfan syndrome, and 1 patient had a bicuspid aortic valve and root aneurysm (Table 5). These patients should undergo an ARR at the time of operation for ATAAD.

3. Aortic root diameter is larger than $4.5 \mathrm{~cm}$ : Acute aortic dissection with root involvement indicates patients have existing aortopathy. If the aortic root is larger than $4.5 \mathrm{~cm}$ at the time of ATAAD, it is likely the aortic root will continue to grow and the patient will need a reoperation for root aneurysm or aortic insufficiency. Ro and colleagues ${ }^{14}$ found patients with ATAAD with an aortic root of $4.7 \mathrm{~cm}$ quickly developed moderate/severe aortic insufficiency and root aneurysm within 3 years after 
TABLE 3. Postoperative outcomes

\begin{tabular}{|c|c|c|c|}
\hline Variables & Total $(n=491)$ & Root repair $(\mathbf{n}=\mathbf{3 0 7})$ & Root replacement $(n=184)$ \\
\hline Intraoperative mortality & $7(1.4)$ & $5(1.6)$ & $2(1.1)$ \\
\hline In-hospital mortality & $41(8.4)$ & $26(8.5)$ & $15(8.2)$ \\
\hline 30-d mortality & $34(6.9)$ & $19(6.2)$ & $15(8.2)$ \\
\hline Myocardial infarction & $6(1.2)$ & $4(1.3)$ & $2(1.1)$ \\
\hline Cerebrovascular accident & $33(6.7)$ & $25(8.2)$ & $8(4.3)$ \\
\hline Atrial fibrillation & $179(36)$ & $107(35)$ & $72(39)$ \\
\hline Pneumonia & $86(18)$ & $55(18)$ & $31(17)$ \\
\hline New-onset renal failure & $49(10)$ & $37(12)$ & $12(6.5)$ \\
\hline Requiring dialysis & $23(4.7)$ & $16(5.2)$ & $7(3.8)$ \\
\hline Permanent dialysis & $9(1.8)$ & $5(1.6)$ & $4(2.2)$ \\
\hline Reoperation for bleeding & $41(8.4)$ & $24(7.8)$ & $17(9)$ \\
\hline Deep sternal infection & $11(2.2)$ & $8(2.6)$ & $3(1.6)$ \\
\hline Sepsis & $14(2.9)$ & $9(2.9)$ & $5(2.7)$ \\
\hline Limb ischemia & $6(1.2)$ & $3(1.1)$ & $3(1.6)$ \\
\hline New-onset paraplegia & $3(0.6)$ & $2(0.7)$ & $1(0.5)$ \\
\hline GI complications & $39(7.9)$ & $26(8.5)$ & $13(7.1)$ \\
\hline Need for tracheostomy & $17(3.5)$ & $10(3.3)$ & $7(3.8)$ \\
\hline Prolonged vent & $266(54)$ & $175(57)$ & $91(49)$ \\
\hline Hours intubated & $44(23,103)$ & $47(25,100)$ & $37(21,108)$ \\
\hline Total length of stay (d) & $11(7,19)$ & $12(7,20)$ & $11(7,18)$ \\
\hline Postoperative length of stay (d) & $10(7,16)$ & $10(7,17)$ & $10(7,16)$ \\
\hline
\end{tabular}

Data presented as median $(25 \%, 75 \%)$ for continuous data and $\mathrm{n}(\%)$ for categoric data. GI, Gastrointestinal.

ATAAD repair. ${ }^{14}$ This criterion has been adopted by many surgeons..$^{20,22,23}$ In patients who needed reoperation for aortic root aneurysm after $\mathrm{ARr}$, the median age was 48 (41-52) years. This finding suggests that younger patients may have been at a higher risk of having an unknown aortopathy that led to developing aortic root aneurysm requiring reoperations. We recommend a more aggressive approach for younger patients. If patients are aged less than 60 years, ARR should be more strongly considered if the aortic root is larger than $4 \mathrm{~cm}$, especially if the surgeon can perform VSARR.

4. Unrepairable aortic valve pathology: If patients have moderate-to-severe aortic stenosis or insufficiency, and the aortic valve is not repairable, we recommend replacement of the entire aortic root instead of only the aortic valve. One could argue to perform aortic valve replacement alone and to preserve the aortic root because it is a less complex operation than ARR. However, if the aortic root is already dissected and diseased, there is less benefit to preserving the aortic sinus segment if the aortic valve cannot also be preserved. At the University of Michigan, all ATAADs are managed by aortic surgeons who are very familiar and comfortable with aortic root procedures. This is another reason that we are more aggressive in performing ARR for ATAAD with unrepairable aortic valve pathology. As reported in the current article, the perioperative mortality and morbidity, and the long-term survival for the ARR group were comparable to the $\mathrm{ARr}$ group even though patients who underwent an ARR were sicker. This finding supports our aortic root approach for patients with ATAAD. Furthermore, our findings are similar to those reported by other experienced aortic centers ${ }^{5,7,8}$ and in a study using International Registry of Acute Aortic Dissection data. ${ }^{6}$ With aggressive ARR, the incidence rate of reoperation for root aneurysm was zero (Table 4).

Some surgeons propose that extensive dissection at the aortic root is another indication for ARR. ${ }^{2,4}$ Nishida and colleagues ${ }^{10}$ found that in patients with ATAAD who underwent ARr, dissection of 2 or more aortic sinuses was an independent predictor of late aortic root events with an HR of 2.2 , including aortic root dilation $3 \mathrm{~mm}$ or more per year, reoperation of the aortic root, moderate to severe aortic 


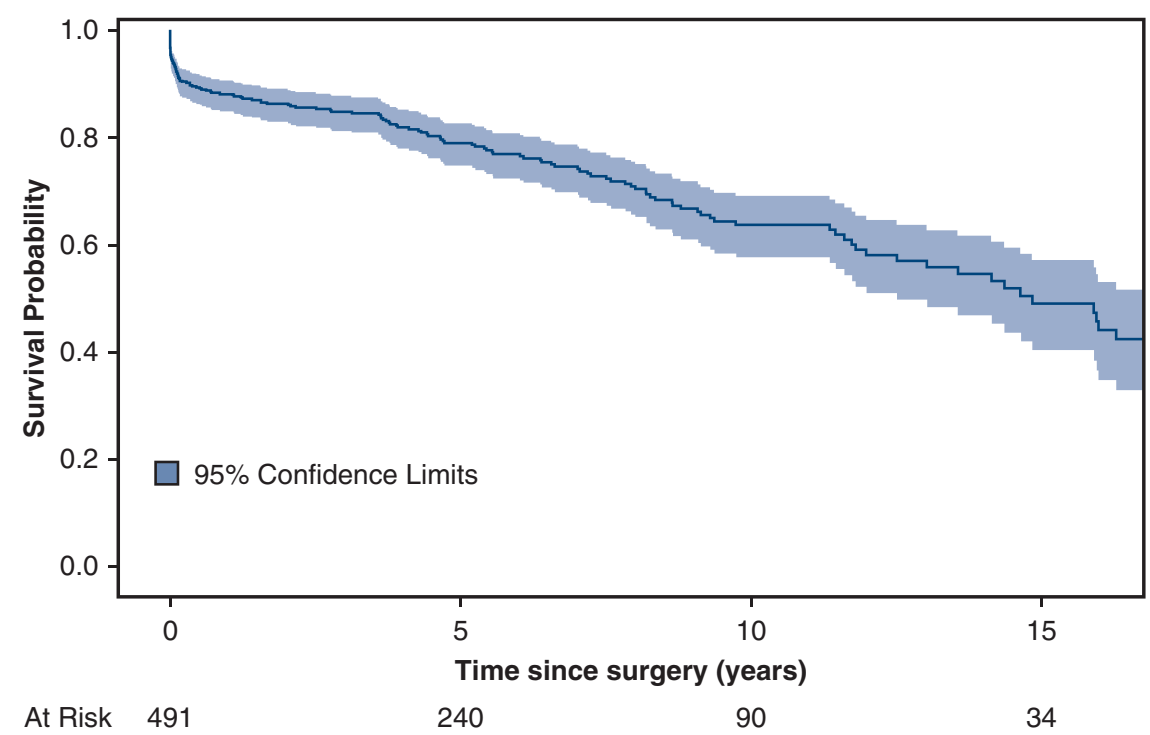

A

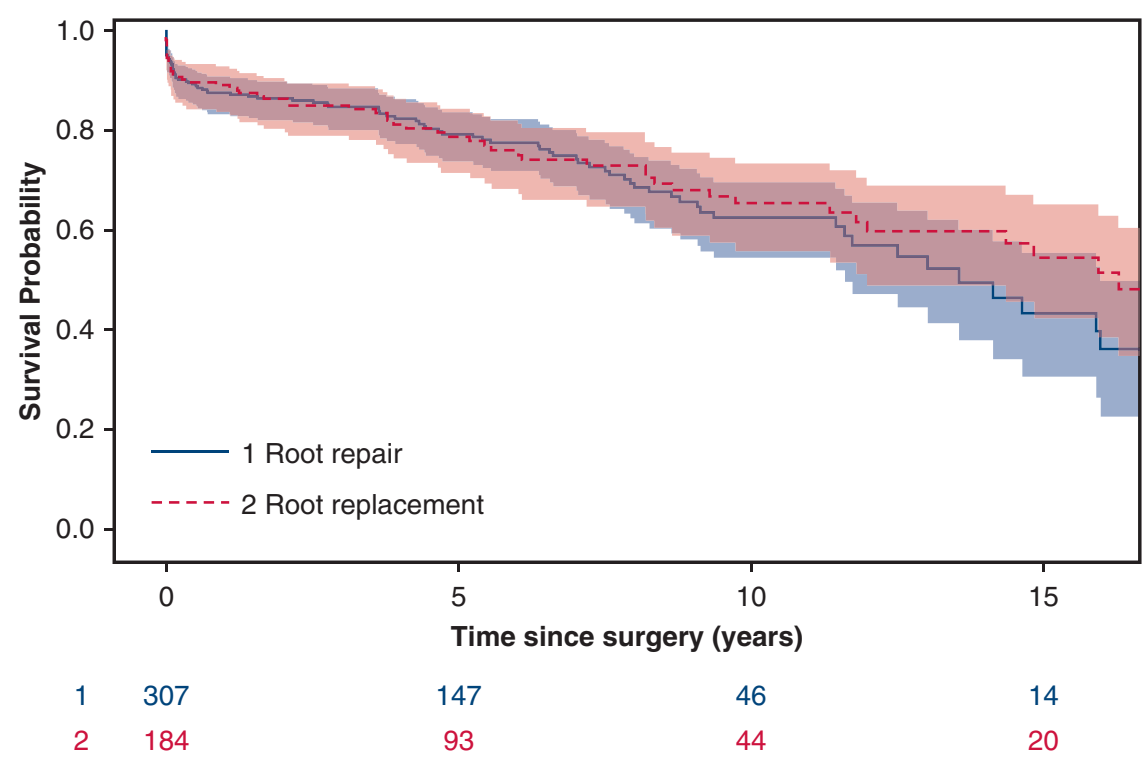

B

FIGURE 1. Long-term survival (Kaplan-Meier analysis) of patients with ATAAD after ARr and ARR with prosthesis. A, Whole cohort. B, Separate subcohorts.

insufficiency, and pseudoaneurysm within 50 months. ${ }^{10}$ However, we did not observe late aortic root events beyond 60 months in our previous study. ${ }^{18}$ If the aortic dissection extends to the left and right sinuses of Valsalva around the coronary ostia, we reinforce the aortic wall around the coronary ostia circumferentially with 5-0 Prolene as an in situ coronary button reimplantation. ${ }^{18}$ Because biological glue was used in the study by Nishida and colleagues ${ }^{10}$ but not in ours, ${ }^{18}$ we suggest the late aortic root events might be partially due to the toxicity of biological glue.
An ARr was performed if the patient did not have an intimal tear at the aortic root, connective tissue disease, unrepairable aortic valve pathology, or an aortic root greater than $4.5 \mathrm{~cm}$. It is important to remove all of the thrombus in the false lumen of the aortic root when performing ARr. After repair, the blood pressure inside the aortic root pushes the dissection flap against the outer layer of the dissected aorta if Teflon felt is not inserted, which keeps the dissection flap attached to the outer layer of the dissected aortic root and lets the dissected aortic wall heal. ${ }^{18}$ We did not resect any part of the aortic root 


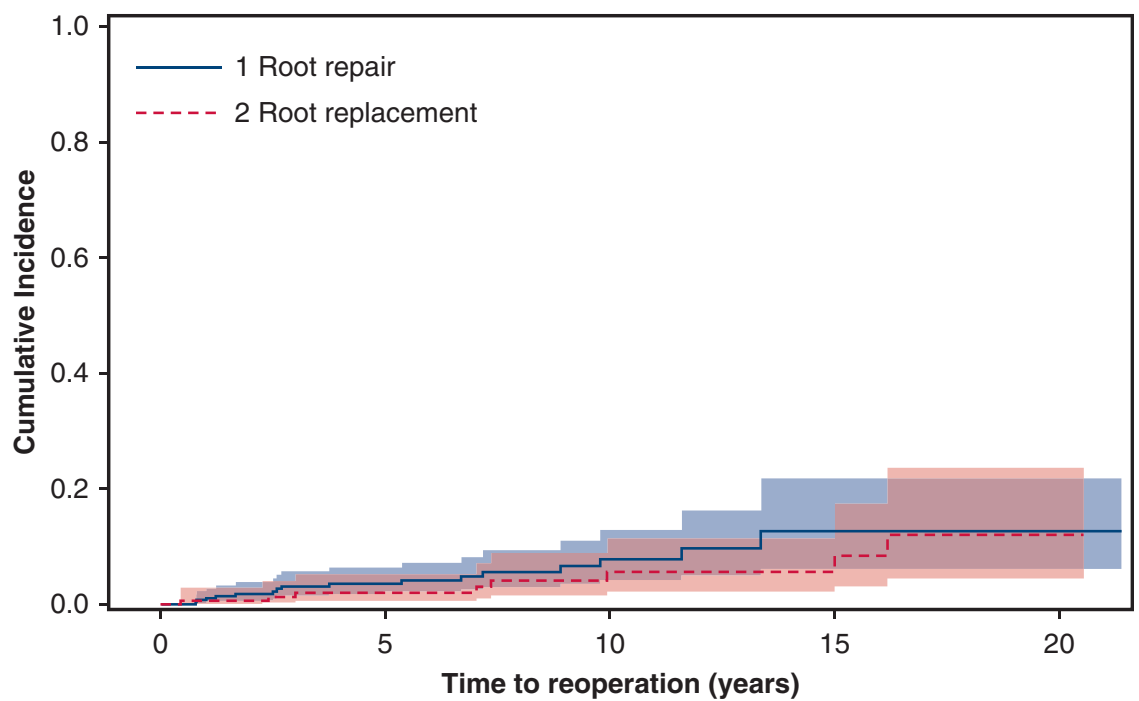

FIGURE 2. Cumulative incidence of reoperation for aortic root pathology only after ATAAD repair with ARr or ARR with prosthesis.

(uni-Yacoub or bi-Yacoub procedure) as described by the Stanford group. ${ }^{5}$ Our previous data showed the dissected aortic root can heal completely without biological glue or Teflon felt, which maintains its natural geometry and minimizes the risk of late aortic insufficiency. ${ }^{18}$

Preservation of the dissected aortic root always has a potential risk of recurrence of aortic root pathology, such as recurrent aortic root dissection, aneurysm/pseudoaneurysm formation, severe aortic insufficiency, and reoperation. In our study, the primary indication of reoperation in the ARr group was aortic root aneurysm (Table 4). Eight of 9 patients who underwent reoperation for the root aneurysm were male (Table 5), and Cox regression showed male patients may potentially have higher risk of reoperation for root pathology than female patients. A more aggressive root approach (eg, VSARR if possible) should be considered for young male patients with ATAAD. In the ARR group, a bioprosthesis was used for $62 \%$ of cases (Freestyle stentless porcine aortic root, Medtronic). Patients with bioprostheses benefited from low neurologic and bleeding complications, but underwent reoperations because of the structural valve deterioration of bioprostheses (Table 4). All the patients undergoing reoperation for aortic root pathology in the ARR group had a bioprosthesis (Freestyle aortic root) during the ATAAD repair. As a result, the overall cumulative incidence of reoperation was similar between the ARr and ARR groups (Figure 2).

\section{Study Limitations}

Our study is limited by being a single-center and retrospective experience, yet with high volume and relatively

TABLE 4. Long-term events

\begin{tabular}{|c|c|c|c|c|}
\hline \multirow[b]{2}{*}{ Variables } & \multicolumn{2}{|r|}{ Root repair } & \multicolumn{2}{|c|}{ Root replacement } \\
\hline & $(\mathbf{n}=\mathbf{3 0 7})$ & Incidence rate (\%/patient-y) & $(n=184)$ & Incidence rate $(\% /$ patient-y) \\
\hline TIA & 3 & 0.2 & 1 & 0.1 \\
\hline Stroke & 4 & 0.2 & 5 & 0.4 \\
\hline Spontaneous bleeding & 3 & 0.2 & 2 & 0.16 \\
\hline Endocarditis & 3 & 0.2 & 1 & 0.1 \\
\hline Reoperation for & 13 & 0.8 & 6 & 0.5 \\
\hline Aortic valve dysfunction & 3 & 0.2 & 6 & 0.5 \\
\hline Aortic insufficiency & 3 & & 5 & \\
\hline Aortic stenosis & 0 & & 1 & \\
\hline Aortic valve endocarditis & 0 & 0 & 0 & 0 \\
\hline Aortic root aneurysm & 9 & 0.5 & 0 & 0 \\
\hline Aortic root pseudoaneurysm & 1 & 0.1 & 0 & 0 \\
\hline
\end{tabular}

TIA, Transient ischemic attack. 
TABLE 5. Details of patients who had reoperation for aortic root aneurysm after aortic root repair during acute type A aortic dissection repair

\begin{tabular}{|c|c|c|c|c|c|c|c|c|c|c|}
\hline \multirow[b]{2}{*}{ Case } & \multirow[b]{2}{*}{ Gender } & \multicolumn{3}{|c|}{ First operation } & \multicolumn{2}{|c|}{ ATAAD repair } & \multicolumn{4}{|c|}{ Reoperation } \\
\hline & & $\begin{array}{c}\text { Age } \\
(y)\end{array}$ & AI & $\begin{array}{c}\text { Aortic } \\
\text { root }(\mathbf{c m})\end{array}$ & $\begin{array}{c}\text { BioGlue } \\
\text { (CryoLife Inc, } \\
\text { Kennesaw, Ga)/ } \\
\text { Felt }\end{array}$ & MPS & $\begin{array}{c}\text { New } \\
\text { diagnosis }\end{array}$ & Age (y) & AI & $\begin{array}{c}\text { Aortic } \\
\operatorname{root}(\mathbf{c m})\end{array}$ \\
\hline 1 & $\mathrm{M}$ & 51 & None & 4.1 & Felt sandwich & $\begin{array}{l}\text { Occlusion of the } \\
\text { right common } \\
\text { carotid artery }\end{array}$ & None & 60 & $\begin{array}{l}\text { Moderate } \\
\text { to severe }\end{array}$ & 5.4 \\
\hline 2 & M & 35 & None & 3.4 & Fibrin glue & None & MFS & 47 & $\begin{array}{l}\text { Moderate } \\
\text { to severe }\end{array}$ & 6.1 \\
\hline 3 & M & 36 & Moderate & Unknown & Unknown & Unknown & None & 50 & Mild & 6.8 \\
\hline 4 & M & 44 & Minimal & 4.2 & None & None & None & 48 & None & 6 \\
\hline 5 & M & 52 & Severe & 4.6 & None & $\begin{array}{l}\text { Acute right sided } \\
\text { MCA stroke }\end{array}$ & None & 53 & None & 5.8 \\
\hline 6 & M & 55 & Mild & Unknown & Unknown & Unknown & None & 61 & Severe & 5.6 \\
\hline 7 & $\mathrm{~F}$ & 69 & None & Unknown & Felt sandwich & Neurologic MPS & None & 70 & Moderate & Unknown \\
\hline 8 & M & 48 & $\begin{array}{l}\text { Moderate } \\
\text { to severe }\end{array}$ & $\begin{array}{l}\text { Not } \\
\text { aneurysmal }\end{array}$ & Felt sandwich & None & MFS & 49 & Moderate & 6 \\
\hline 9 & M & 41 & Moderate & $\begin{array}{l}\text { Not } \\
\quad \text { aneurysmal }\end{array}$ & Felt sandwich & None & BAV & 50 & Severe & 5.6 \\
\hline
\end{tabular}

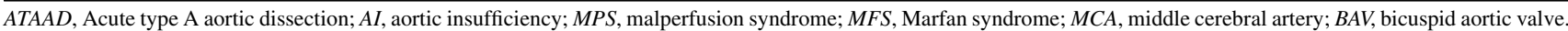

long-term follow-up. Because the follow-up of reoperation was not $100 \%$ complete, we might underestimate the rate of reoperation in both $\mathrm{ARr}$ and ARR groups. Bioprostheses were used in the majority $(62 \%)$ of our ARR procedures; therefore, our study represents the outcomes of $\mathrm{ARr}$ and bioprosthetic ARR in ATAAD. At the University of Michigan, the patients with ATAAD were managed mainly by aortic surgeons. Each surgeon performs 15 to 25 ATAAD cases per year and elective aortic root cases routinely. Our experience may not apply in general.

\section{CONCLUSIONS}

In ATAAD, both ARr and ARR are appropriate operations for select patients with good short- and long-term outcomes. An ARR should be considered for patients with

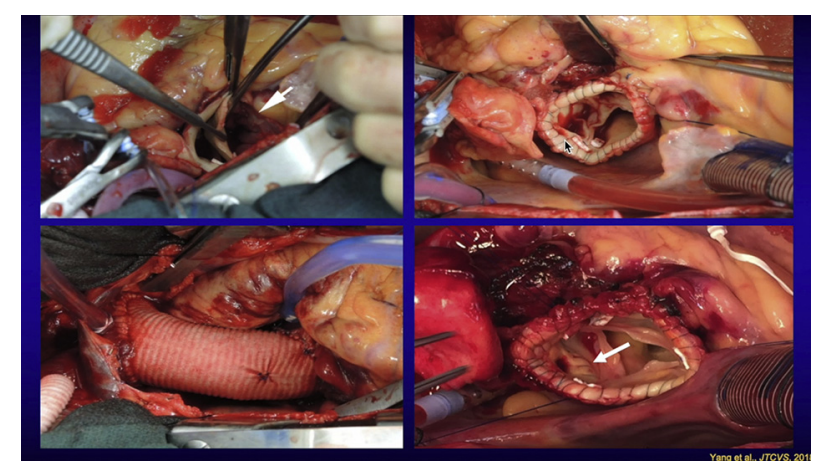

VIDEO 1. Discussion of aortic root management in ATAAD with power point presentation. Video available at: https://www.jtcvs.org/article/ S0022-5223(18)33113-1/fulltext.
ATAAD with an intimal tear at the aortic root, root aneurysm $4.5 \mathrm{~cm}$ or greater, connective tissue disease, or unrepairable aortic valvulopathy. ARr with preservation of the aortic root increased the potential risk of late reoperation for aortic root aneurysm.

\section{Webcast}

You can watch a Webcast of this AATS meeting presentation by going to: https://aats.blob.core.windows.net/ media/18May01/28ABC\%202.Aortic\%20Endovascular/S 85\%20-\%20Part\%201/S85_4_webcast_024733949.mp4.

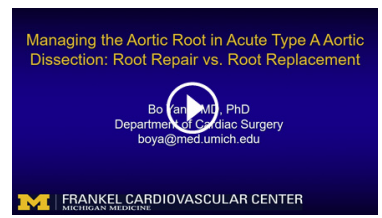

\section{Conflict of Interest Statement}

Authors have nothing to disclose with regard to commercial support.

\section{References}

1. Berretta P, Patel HJ, Gleason TG, Sundt TM, Myrmel T, Desai N, et al. IRAD experience on surgical type A acute dissection patients: results and predictors of mortality. Ann Cardiothorac Surg. 2016;5:346-51.

2. Castrovinci S, Pacini D, Di Marco L, Berretta P, Cefarelli M, Murana G, et al. Surgical management of aortic root in type A acute aortic dissection: a propensity-score analysis. Eur J Cardiothorac Surg. 2016;50:223-9.

3. Peterss S, Dumfarth J, Rizzo JA, Bonaros N, Fang H, Tranquilli M, et al. Sparing the aortic root in acute aortic dissection type A: risk reduction and restored integrity of the untouched root. Eur J Cardiothorac Surg. 2016;50:232-9. 
4. Leshnower BG, Chen EP. When and how to replace the aortic root in type A aortic dissection. Ann Cardiothorac Surg. 2016;5:377-82.

5. Chiu P, Trojan J, Tsou S, Goldstone AB, Woo YJ, Fischbein MP. Limited root repair in acute type A aortic dissection is safe but results in increased risk of reoperation. J Thorac Cardiovasc Surg. 2018;155:1-7 e1.

6. Di Eusanio M, Trimarchi S, Peterson MD, Myrmel T, Hughes GC, Korach A, et al. Root replacement surgery versus more conservative management during type A acute aortic dissection repair. Ann Thorac Surg. 2014;98: 2078-84.

7. Fleischman F, Elsayed RS, Cohen RG, Tatum JM, Kumar SR, Kazerouni K, et al. Selective aortic arch and root replacement in repair of acute type A aortic dissection. Ann Thorac Surg. 2018;105:505-12.

8. Halstead JC, Spielvogel D, Meier DM, Rinke S, Bodian C, Malekan R, et al. Composite aortic root replacement in acute type A dissection: time to rethink the indications? Eur J Cardiothorac Surg. 2005;27:626-33.

9. Martin KA, Merenick BL, Ding M, Fetalvero KM, Rzucidlo EM, Kozul CD, et al. Rapamycin promotes vascular smooth muscle cell differentiation through insulin receptor substrate-1/phosphatidylinositol 3-kinase/Akt2 feedback signaling. J Biol Chem. 2007;282:36112-20.

10. Nishida H, Tabata M, Fukui T, Takanashi S. Surgical strategy and outcome for aortic root in patients undergoing repair of acute type A aortic dissection. Ann Thorac Surg. 2016;101:1464-9.

11. Valdis M, Adams C, Chu MWA, Kiaii B, Guo L. Comparison of outcomes of root replacement procedures and supracoronary techniques for surgical repair of acute aortic dissection. Can J Surg. 2017;60:198-204.

12. Kamohara K, Koga S, Takaki J, Yoshida N, Furukawa K, Morita S. Long-term durability of preserved aortic root after repair of acute type A aortic dissection. Gen Thorac Cardiovasc Surg. 2017;65:441-8.

13. Saczkowski R, Malas T, Mesana T, de Kerchove L, El Khoury G, Boodhwani M. Aortic valve preservation and repair in acute type A aortic dissection. Eur J Cardiothorac Surg. 2014;45:e220-6.

14. Ro SK, Kim JB, Hwang SK, Jung SH, Choo SJ, Chung CH, et al. Aortic root conservative repair of acute type A aortic dissection involving the aortic root: fate of the aortic root and aortic valve function. J Thorac Cardiovasc Surg. 2013;146: 1113-8.

15. Yang B, DeBenedictus C, Watt T, Farley S, Salita A, Hornsby W, et al. The impact of concomitant pulmonary hypertension on early and late outcomes following surgery for mitral stenosis. J Thorac Cardiovasc Surg. 2016;152: 394-400.e391.

16. Centers for Disease Control and Prevention; National Center for Health Statistics. National Death Index. Available at: http://www.cdc.gov/nchs/ndi/index. htm. Accessed December 27, 2017.

17. Yang B, Patel HJ, Sorek C, Hornsby WE, Wu X, Ward S, et al. Sixteen-year experience of David and Bentall procedures in acute type A aortic dissection. Ann Thorac Surg. 2018;105:779-84.

18. Yang B, Malik A, Waidley V, Wu X, Norton EL, Williams DM, et al. Shortterm outcomes of a simple and effective approach to aortic root and arch repair in acute type A aortic dissection. J Thorac Cardiovasc Surg. 2018; 155:1360-70.e1361.

19. Tanaka K, Morioka K, Li W, Yamada N, Takamori A, Handa M, et al. Adventitial inversion technique without the aid of biologic glue or Teflon buttress for acute type A aortic dissection. Eur J Cardiothorac Surg. 2005;28:864-9.

20. Rylski B, Bavaria JE, Milewski RK, Vallabhajosyula P, Moser W, Kremens E, et al. Long-term results of neomedia sinus Valsalva repair in 489 patients with type A aortic dissection. Ann Thorac Surg. 2014;98:582-9.

21. Fann JI, Smith JA, Miller DC, Mitchell RS, Moore KA, Grunkemeier G, et al. Surgical management of aortic dissection during a 30-year period. Circulation. 1995;92:II113-21.

22. Kunihara T, Neumann N, Kriechbaum SD, Aicher D, Schafers HJ. Aortic root remodeling leads to good valve stability in acute aortic dissection and preexistent root dilatation. J Thorac Cardiovasc Surg. 2016;152:430-6.e431.

23. Leshnower BG, Myung RJ, McPherson L, Chen EP. Midterm results of David V valve-sparing aortic root replacement in acute type A aortic dissection. Ann Thorac Surg. 2015;99:795-801.

Key Words: aortic dissection, aortic root replacement, aortic root repair, operative outcome, acute type A aortic dissection

\section{Discussion}

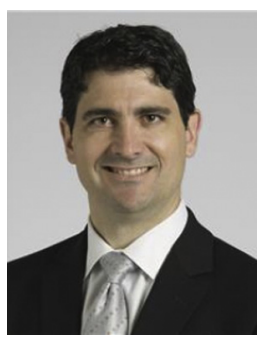

Dr E. Roselli (Cleveland, Ohio). Great job. You demonstrated a mortality of $9 \%$ and $10 \%$ in those 2 groups, really good outcomes for acute type A dissection. The first couple of questions I have for you are easy ones; they are technical questions.

Number one, you talked about these indications for when you do a total root and when you do a root repair, but we often see some people who are elderly and have some degenerative valve disease or sometimes a bicuspid valve that is degenerated with a normal size root. What about patients in whom you do a super coronary ascending graft and a valve replacement, or maybe a patient in whom one of the sinuses dilated like a noncoronary sinus, do kind of a Wolf procedure, or I know folks will do that, do you use any of those techniques or just go straight to a root replacement if you have those issues, and why?

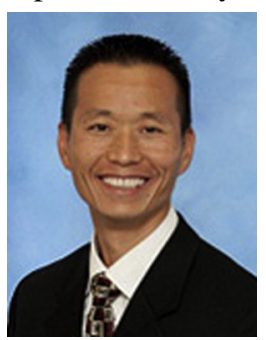

Dr B. Yang (Ann Arbor, Mich). Personally, if I see those I just do a total root replacement. I know Dr Patel has chosen inclusion root in this kind of pathology.

Dr Roselli. You won't just put a bioprosthesis in and do a super coronary graft? The elderly patient who comes in with ATAAD, the root size is preserved but the patient has moderate to severe aortic stenosis, would you just do an aortic valve replacement and a super coronary graft, were these patients excluded from your series, or do you just jump right to a total root in those patients? It felt like some of the patients were missing. There is a subset of our population in whom we do that.

Dr Yang. I did a valve replacement in 1 patient because of the condition you described. However, I won't recommend to save a dissected, diseased aortic root if the aortic valve is not salvageable. Personally I think it's tricky, and you worry about tearing the intima in the aortic root. So most of the time, I just do a total root.

Dr Roselli. Okay. So you just don't even use that strategy?

Dr Yang. Yes, that's correct. To me personally, there is not much difference between an AVR and aortic root replacement, and an aortic root replacement completely eliminates the dissected root.

Dr Roselli. My other technical question is about the inclusion root. We have learned historically that the inclusion technique of dealing with the coronaries can increase the risk of pseudoaneurysms, so most folks will do a button technique when they do a total root replacement. Can you tell us a bit about why you chose to do the inclusion root and have you had any issues with the coronaries in that 
situation, or what can you teach us about that so we don't have to have that pseudoaneurysm problem?

Dr Yang. That's a great question. I personally use total root replacement for all dissected aortic root. Drs Deeb and Patel have done this inclusion root. The key thing is at the coronary buttons, we always try to do full-thickness bites around the anastomosis, even side-to-side anastomsis for coronary artery ostial implantation. So that's probably the key, and Dr Patel can jump in for his experience.

Dr Roselli. You have had no pseudoaneurysms with the coronaries in this population?

Dr Yang. No, not from this study.

Dr Roselli. Great. Another question is, you have looked at the rate of reoperation as a cumulative analysis, which I think is a little unusual, especially because you only had 140 patients at risk at 5 years and 47 patients at risk at 10 years and 20 patients at risk at 15 years. You didn't use an estimated kind of analysis to do that. I think that methodology may be flawed when you are looking at freedom from reoperation. We were looking at the outcomes in these patients. You demonstrated a 10-year survival of approximately $60 \%$, a 15 -year survival of only $50 \%$ despite the fact that these patients were young with a mean age of 60 years and only approximately $20 \%$ of patients with coronary artery disease. So it seems to me that we are not gathering all the events here, and with these patients I think we should be looking at a competing risk kind of analysis when we look at these data.

Can you give us some additional data or understanding about cause of death or what happened to these patients' downstream aorta? I think when we talk about dissection, that is important information. I know you are focused on the root, but I think using $40 \%$ of our patients at 10 years is unreliable.

Dr Yang. We used Gray's test to calculate the cumulative incidence of reoperation for the root pathology adjusting death as a competing factor. The method is correct from a statistical standpoint. However, we did not have $100 \%$ follow-up of the reoperation; therefore, it could underestimate the reoperation rate in both groups. Regarding the survival, looking at 15 years, the numbers are relatively small, that's why I only reported 10-year mortality, and survival is $60 \%$ to $65 \%$. So I think beyond that, because the numbers are so small, that may not be reliable data.

Dr Roselli. Do you have any cause of death data?

Dr Yang. No, I don't. I used the National Death Index to get the information for late mortality.

Dr Roselli. One final last question, and this is an easy one. You showed us those 9 patients who had reoperations, and you pointed out that they were young. Did you notice any other association in those patients, for example, were you able to look at their original computed tomography scan, did they have moderately dilated aortic roots at the time, because most of them developed a root aneurysm and you wished maybe you had done something different at that time? And in those young people, is there a role for a David reimplantation procedure? I know your institution is good at it, and we have all gotten better over the last few years.

Dr Yang. That's a great question. We did go back to the operative reports instead of computed tomography scans, and I didn't put the information here, but of those 9 patients, 6 documented a normal root and 3 documented unknown, didn't say anything about the size of the root, so I cannot say anything about that. And based on the judgment of the surgeon at that time, I believe it should not be aneurysmal. I don't have the details.

Dr Roselli. But some of them were dilated at the time?

Dr Yang. I don't know, because 3 cases I didn't know, there was no documentation, and 6 cases had a normal root.

Dr Roselli. And the role for reimplantation?

Dr Yang. The role for reimplantation is a great question. We lately would do the David reimplantation. Yes, for the young, healthy patient with a normal aortic valve, we do reimplantation, but we excluded that group from this study. The reason we did is because that is a special group; they are younger, healthier, and really selective patients. So we just excluded that group of patients from this study.

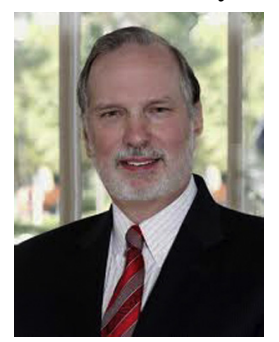

Dr J. Bavaria (Philadelphia, Pa). I would just like to reiterate the slide here, and I need to ask a quick question. When you said the reintervention rate, was that a proximal reintervention rate or just a proximal and a distal reintervention rate?

Dr Yang. That's a great question. This reoperation is only for the root.

Dr Bavaria. So this is a proximal reintervention rate?

Dr Yang. Not including the arch, only in the root, the primary indication is the root. It is not the arch. We excluded that.

Dr Bavaria. So it's a root reintervention rate?

Dr Yang. Exactly, very specific for the root.

Dr Bavaria. So let's transpose that right there, go back to that slide, that one right there. This just reiterates what $\mathrm{Dr}$ Roselli is saying, which is that reintervention rates are absolutely, positively not an appropriate way to report the failure of the index operation. So we have a $40 \%$ mortality rate at 10 years in a group of patients who are 60 years old. They are dying because of their aortas. So we need to beef it up here a bit if we are going to be doing this kind of stuff and make sure that we present it the right way. I just want to make a clarion call for that.

Dr Yang. To answer your question, this analysis actually is a risk-adjusted analysis using death as a competing factor. 
We put death as a competing factor to calculate this cumulative incidence. So we think the statistical method was correct.

Dr Bavaria. Go to your last slide, the conclusion slide. So the last conclusion there, I think we have to take this with a grain of salt. I agree with your point about a root procedure here, but it really should be a David V operation. I don't think we should be doing prophylactic root operations in patients aged less than 55 years for no other reason than just because it looks bad unless it is a valve-sparing operation. I just want to make that point.

Dr Yang. I agree. For those patients, we have been doing David procedures. 